\title{
Clinical pattern, associated factors and impact of disease on quality of life among individuals with melasma visiting the dermatology clinic at Teaching Hospital Karapitiya
}

\author{
Wanniarachchi CG ${ }^{1}$, Wijenayaka BKS ${ }^{1}$ \\ ${ }^{\prime}$ Dermatology Unit, Teaching Hospital Karapitiya, Sri Lanka. \\ Correspondence: Dr. C G Wanniarachchi \\ e-mail: cgwanniarachchi@gmail.com \\ (D) https://orcid.org/0000-0003-4902-4989
}

\begin{abstract}
Introduction: Melasma is an acquired form of hypermelanosis that results in symmetrical, brownish pigmentation commonly on the face. This study was aimed to assess its clinical pattern, associated factors and impact of melasma on quality of life.

Methods: A clinic-based descriptive cross-sectional study was conducted recruiting all individuals with melasma, attended to the dermatology clinic of Teaching Hospital Karapitiya for seven months. Both a selfreported questionnaire and an interviewer-administered data record sheet were used for data collection.

Results: There were 172 individuals with melasma. Dominated by females $(\mathrm{n}=168,97.7 \%)$ and $52.3 \%(\mathrm{n}=90)$ were with Fitzpatrick type V skin. The mean age of onset was 47.2 years and the predominant pattern was malar pattern $(58.1 \%)$. Most common associated factor was sun exposure $(\mathrm{n}=76,44.7 \%)$, followed by, menstrual irregularities $(20.5 \%)$, hormonal treatment $(19.4 \%)$, family history $(19.8 \%)$ and pregnancy $(10.4 \%)$. Though $65.1 \%$ reported exposure to sun more than two hours in the midday, only $31.4 \%(n=54)$ used a sun protection method and sunscreens were used by only $4.65 \%$,

The mean MASI (Melasma Area and Severity Index) score was 12.7, with a range of 1.5 to 30.9. There were statistically significant correlations with family history, duration of sun exposure and the use of facial cosmetics $(p<0.05)$. Mean Melasma Quality of Life Score (MELASQOL) was 28.86, but there was no significant correlation between MASI score and MELASQOL (Pearson correlation $=0.548, p>0.05$ ).

Conclusions: Melasma starts at an older age in our study population. It causes a significant negative effect on psychosocial aspects of quality of life though not related to severity, suggesting that treatment decisions should not depend on severity. Appropriate usage of cosmetics and sunscreens must be advised.
\end{abstract}

Keywords: Associated factors, Karapitiya, melasma, MASI score, MELASQOL, quality oflife, Sri Lanka

\section{Introduction}

Melasma is an acquired, form of hypermelanosis most prevalent in darker skin phenotypes. It is frequently seen in women and mostly starts between the ages of 20 to 40 years. It is characterised by irregular, light to dark brown macules and patches in sun-exposed areas, commonly the face $(1,2)$.
The precise cause of melasma is unknown, but several factors have been linked to its exacerbation. However, by considering the histopathological findings, recent studies revealed that melasma is not only a pigmentary disorder but a photo-aging disorder as well (1 - 3). Based on distribution over the face, three clinical patterns are recognised. 
The centro-facial pattern involves the forehead, cheeks, upper lip, nose and chin, while malar pattern involves the cheeks and nose. The mandibular pattern involves the skin over the ramus of mandible $(2,4,5)$.

The precise cause of melasma is unknown and is thought to be multifactorial. Several predisposing/ aggravating factors are linked to melasma, namely, genetic predisposition, female hormonal activity, UV exposure, certain cosmetics and drugs such as photo-toxic drugs and anti-seizure drugs. Pregnancy and oral contraceptives play a major role as hormonal factors. This is evidenced by the fading of the pigmentation after parturition, discontinuation of oral contraceptives and avoidance of sun $(1,2$, 4-6).

Its prevalence varies among different countries due to the variation of the Fitzpatric skin type in different ethnic groups and UV exposure within various geographic locations. Therefore, it is common in Caucasian women particularly in Latin America, Middle East and Asia (7).

The severity of melasma is assessed by the Melasma Area and Severity Index (MASI) which is based on the surface area involved, darkness, and homogenicity of pigmentation $(4,8)$.

For the reason of involvement of the face most commonly and the female gender being affected mostly, the disease has a significant emotional and psychological impact on the quality of life $(1,9)$. The quality of life of melasma is assessed by the MELASQOL scale with a standard structured questionnaire which includes ten questions assessing psycho-social aspect of quality of life $(4,10)$.

Treatment of melasma usually combines the elimination of possible causative factors, the use of sunscreens, hypo-pigmenting agents and cosmetic procedures. Combination of therapeutic modalities generally has better efficacy than monotherapy. The use of sunscreen is essential in the prevention of melasma and for the enhancement of the efficacy of other topical therapies (7).

There are wider differences in different ethnicities in prevalence, distribution, severity and pattern of this disease and there is no available literature on studies done in Sri Lanka. We planned to study the clinical pattern, associated factors and impact of melasma on quality of life of affected patients. Identification of common associated factors in our population will aid planning the treatment strategies and also would provide background information to educate people to avoid possible exacerbating factors, and to enhance the treatment outcome and the compliance.

\section{Methods}

A clinic-based descriptive cross-sectional study was conducted in the dermatology clinic at Teaching Hospital Karapitiya from October 2017 to May 2018. Patients, who were clinically diagnosed as melasma by characteristic clinical features of pigmented macules and patches with irregular geographic borders, were enrolled to the study. Only the patients who can read and understand the questionnaire were included. Patients with co-existent other pigmentary disorders such as lichen planus pigmentosus, erythema dyschromicum perstans, ochronosis, and people with pigmentary demarcated lines in addition to melasma were excluded from the study.

A pretested self-reported questionnaire with eighteen close ended questions and an intervieweradministered data record sheet were used for data collection. The questionnaire included demographic data, age at onset of the disease, known exacerbating factors and skincare habits. The average duration of exposure to the sun per day and the usage of sun protection methods were recorded.

Patients were examined to assess skin phenotype, distribution, intensity, homogeneity of pigmentation and recorded in the data record sheet. MASI score was calculated using these data with the clinical assessment of forehead, both malar regions and chin based on three variables: percentage of the total area involved (A), darkness (D), and homogeneity $(\mathrm{H})$. The value assigned for the corresponding percentage area involved is, $0=$ no involvement; $1=<10 \% ; 2=10-29 \% ; 3=30-49 \%$; $4=50-69 \% ; 5=70-89 \%$; and $6=90-100 \%$ involvement. The darkness of the melasma (D) is graded on a scale of 0 to $4: 0=$ without evidence of hyperpigmentation; 1 = barely visible hyperpigmentation; 2 = mild hyperpigmentation; $3=$ moderate hyperpigmentation; $4=$ severe hyperpigmentation. 
Homogeneity of the hyperpigmentation $(\mathrm{H})$ is graded on a scale of 0 to 4 : $0=$ without evidence of hyperpigmentation; $1=$ specks of involvement; $2=$ small patchy areas of involvement $<1.5 \mathrm{~cm}$ diameter; $3=$ patches of involvement $>2 \mathrm{~cm}$ diameter; 4=uniform skin involvement without any clear areas). Total MASI score was calculated with the formula of Forehead $0.3(\mathrm{D}+\mathrm{H}) \mathrm{A}+$ right malar 0.3 $(\mathrm{D}+\mathrm{H}) \mathrm{A}+$ left malar $0.3(\mathrm{D}+\mathrm{H}) \mathrm{A}+\operatorname{chin} 0.1(\mathrm{D}+\mathrm{H}) \mathrm{A}$ (13). The distribution of MASI score was categorized using the quartile method, with MASI score of $<7.2$ defining as a mild disease, between 7.2 and 11.95 as moderate disease, between 11.96 and 18.07 as severe disease, and $>18.07$ as a very severe disease to analyse the significance of aggravating factors and MASI score (11).

A validated Sinhala translation of MELASQOL was used to assess the quality of life of the patients. The English version of MELASQOL was translated to Sinhala using a standard procedure after taking permission from the original author and copyright holder of the English version Professor Rajesh Balkrishnan (10). This was validated using the Sinhala adaptation of short version of the QoL assessment instrument of World Health Organization (WHOQOL-BREF). The Sinhala-MELASQOL showed negative correlation with psycho-social domains of the WHOQOL-BREF (Spearman correlation coefficient, $-0.389 ; p<0.05$ for social domains and $-0.449 ; p<0.05$ for psychological domains) demonstrating that the SinhalaMELASQOL as an acceptable and reliable instrument to evaluate the quality of life in patients with melasma (12). MELASQOL scale measures the psychosocial aspect of disease. It is a 10 question scale, which requires the patients to rate how they feel about each issue rated on a Likert scale of 1 (not bothered at all) to 7 (bothered all the time). The score ranges from 10-70 with higher the score more the impairment of quality of life.

The ethical approval for the study was obtained from the Ethics Review Committee of the Faculty of Medicine, University of Ruhuna and conducted with the prior permission of the relevant administrative authorities. The participation was entirely voluntary and informed consent was obtained for the study as well as for the publication with photographs. Participants were ensured of the freedom to withdraw from the study at any stage. Confidentiality was met throughout the study and the individual identity of participants has not been disclosed. All data were analysed using a database created with SPSS and $p<0.05$ was considered as statistically significant.

\section{Results}

A total of 172 individuals with melasma were included in the study. The mean age (SD) of the participants was $54.97(+/-8.34)$ years, with an age range between 28 - 76 years. The majority of them have been studied up to level of secondary education $(36.6 \%, \mathrm{n}=63)($ Table 1$)$.

Females dominated the study participants $(n=168$, 97.7\%). All the participants were of Fitzpatrick skin type IV $(n=82,47.7 \%)$ and $V(n=90,52.3 \%)$. The age of onset of melasma for most of them was between 40-49 years with a mean age (SD) of 47.2 (+/-9.78) years. The predominant pattern observed was malar pattern (58.1\%) Mandibular only pattern was not observed in the study sample (Table 1). (Figures 1-4).

When considering the associated factors, majority $(n=76,44.7 \%)$ of individuals have noted exacerbation due to exposure to sun and $34(19.8 \%)$ individuals reported a positive family history of melasma. Among 138 women who reported of being pregnant, only $10.4 \%$ declared pregnancy as an aggravating factor (Table 2 ).

Majority $(65.1 \%)$ of the patients studied were exposed to the sun $>2$ hours in midday where the intensity of sunlight is in its peak. Overall, only 54 (31.4\%) use a sun protection method, namely, sunscreens, shades, and clothes. Among them, sunscreens were used by only $14.8 \%$ of individuals; which is $4.7 \%$ from the total number of study participants. Interestingly, majority has not responded to the question whether they use sun protection method or not. Concerning skincare habits, 50\% declared regular application of cosmetics to face, with herbal and non-herbal products in almost equal amounts (45.7\% and $48.6 \%$ respectively) (Table 3 ). 


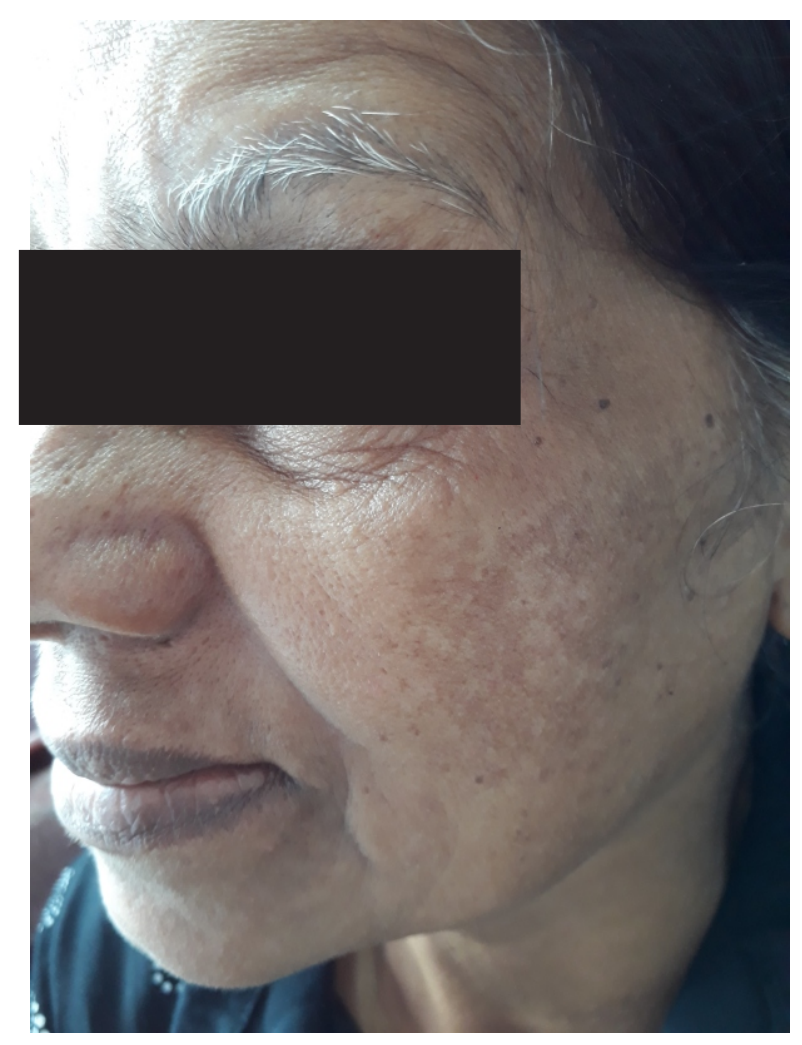

Figure 1: Malar pattern, Grade 2 pigmentation, Grade 2 homogeneity

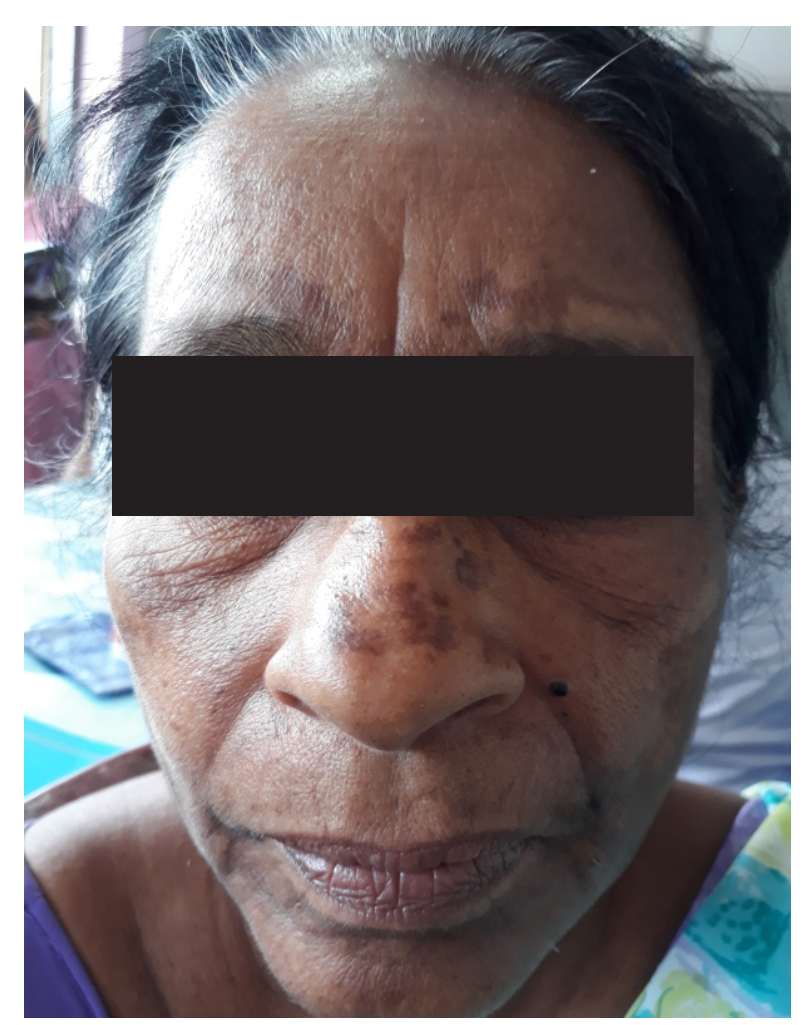

Figure 3: Centro-facial pattern, Grade 3 pigmentation, Grade 3 homogeneity

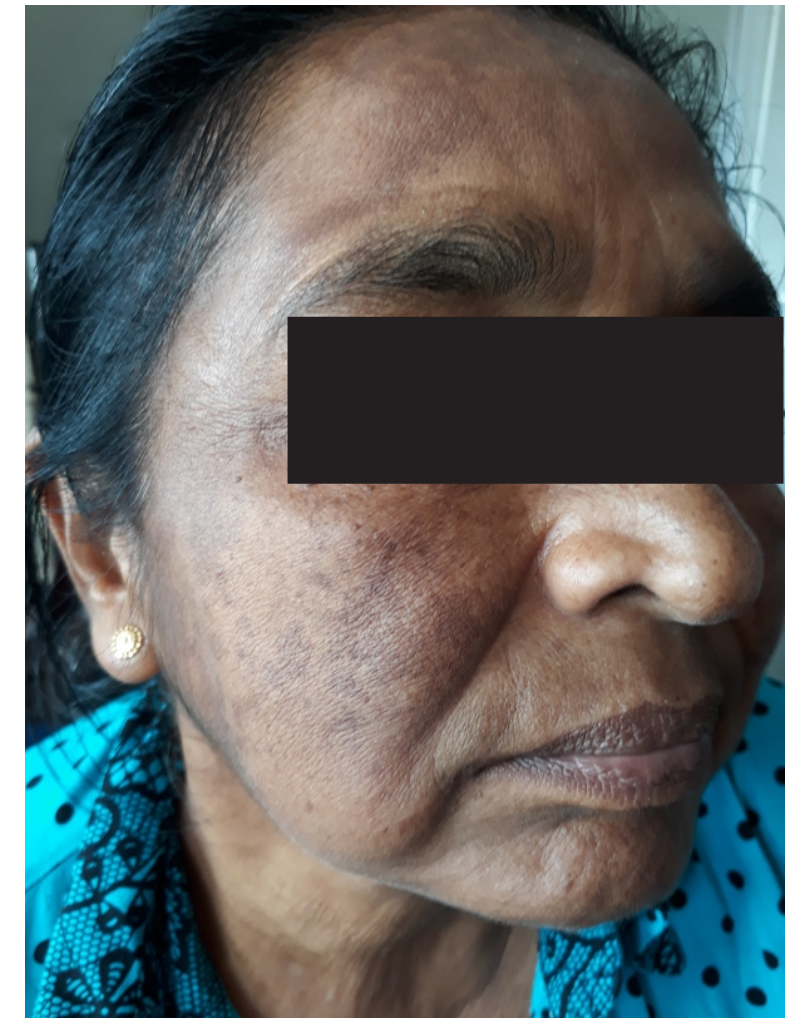

Figure 2: Centro-facial pattern, Grade 3 pigmentation, Grade 2 homogeneity

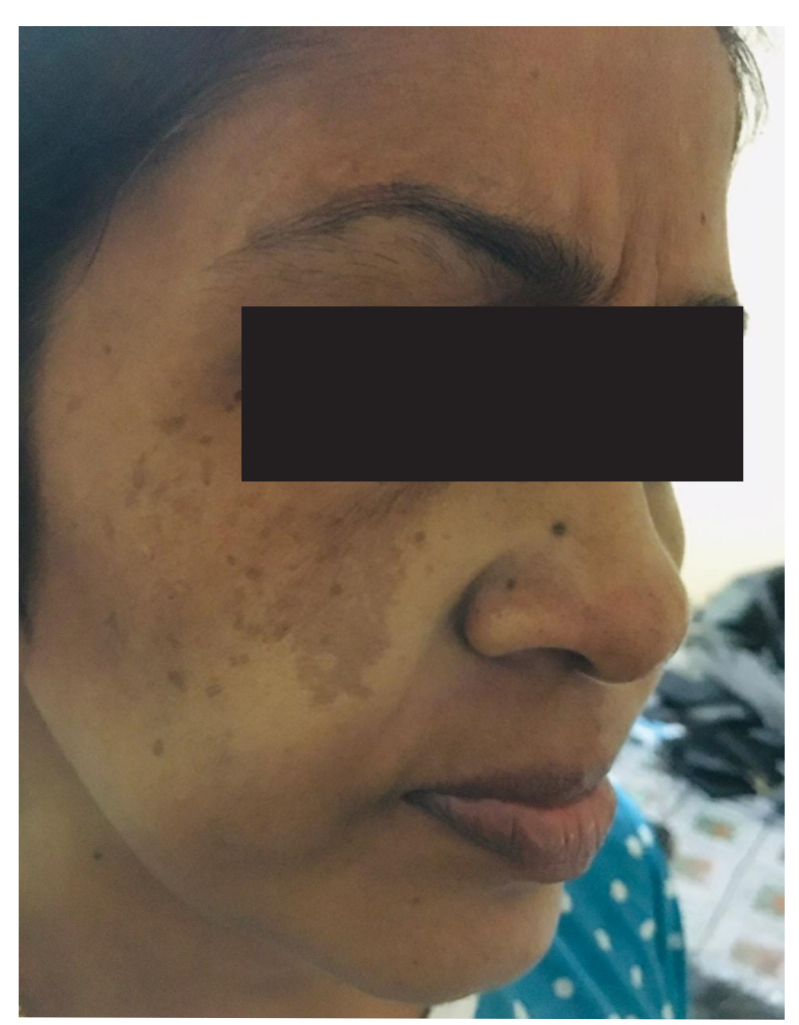

Figure 4: Malar pattern, Grade 2 pigmentation, Grade 3 homogeneity 
Table 1: Demographic details and disease characteristics of melasma patients

\begin{tabular}{llcc}
\hline & Category & Frequency & Percentage \\
\hline Age in years & $20-29$ & 01 & $0.6 \%$ \\
& $30-39$ & 06 & $3.5 \%$ \\
& $40-49$ & 39 & $22.7 \%$ \\
& $50-59$ & 75 & $43.6 \%$ \\
& $>60$ & 51 & $29.7 \%$ \\
\hline Sex & Female & 168 & $97.7 \%$ \\
\hline Educational level & Male & 04 & $2.3 \%$ \\
& No & 08 & $4.7 \%$ \\
& Gr 1-5 & 46 & $26.7 \%$ \\
& Gr 6-11 & 63 & $36.6 \%$ \\
& A/L & 39 & $22.7 \%$ \\
& Higher education & 14 & $8.1 \%$ \\
\hline Fitzpatrick skin type & Type IV & 82 & $47.7 \%$ \\
& Type V & 90 & $52.3 \%$ \\
\hline Age of Onset & $<30$ & 04 & $2.4 \%$ \\
& $30-39$ & 34 & $20.2 \%$ \\
& $40-49$ & 61 & $36.3 \%$ \\
& $50-59$ & 47 & $28.0 \%$ \\
& $>60$ & 22 & $13.1 \%$ \\
\hline & Centro-facial & 72 & $41.9 \%$ \\
& Malar & 00 & $58.1 \%$ \\
& Mandibular only & $00.0 \%$ \\
\hline
\end{tabular}

Table 2: Associated factors of melasma in the study sample

\begin{tabular}{lllll}
\hline Factor & $\begin{array}{l}\text { Positive } \\
\text { Frequency }\end{array}$ & Percentage & $\begin{array}{l}\text { Negative } \\
\text { Frequency }\end{array}$ & Percentage \\
\hline Family history & 34 & $19.8 \%{ }^{*}$ & 138 & $80.2 \%$ \\
Pregnancy & 10 & $10.4 \%$ & 96 & $89.6 \%$ \\
Hormone treatment & 32 & $19.4 \%$ & 133 & $80.6 \%$ \\
Menstrual irregularities & 34 & $20.5 \%{ }^{*}$ & 132 & $79.5 \%$ \\
Sun exposure & 76 & $44.7 \%$ & 94 & $55.3 \%$ \\
\hline
\end{tabular}

* There were 6 non-responders in the category of menstrual irregularities 
Table 3: Sun exposure, protection behaviour and facial skin care habits among the patients

\begin{tabular}{lcc}
\hline & Frequency & Percentage \\
\hline Sun exposure in peak hours & 60 & $34.9 \%$ \\
$<2$ hours & 112 & $65.1 \%$ \\
$>2$ hours & & \\
\hline Type of protection used & 04 & $7.4 \%$ \\
Sunscreens & 08 & $14.8 \%$ \\
Dresses & 29 & $53.7 \%$ \\
Sunshades & 09 & $16.7 \%$ \\
Dresses and shades & 04 & $7.4 \%$ \\
Sunscreens and shades & 26 & $15.1 \%$ \\
No protection & & \\
\hline Type of cosmetics & 32 & $45.7 \%$ \\
Herbal creams & 34 & $48.6 \%$ \\
Non-Herbal creams & 04 & $5.7 \%$ \\
Other &
\end{tabular}

The mean MASI score in the study population was $12.7+/-7.07$ which ranged from 1.5 to 30.9 .

According to the level of melasma severity, $85.3 \%$ of persons with a positive family history had a higher MASI score of more than $25^{\text {th }}$ centile, with a statistically significant association. $(p=0.033)$. Considering sun exposure, $75.9 \%$ of the study participants who were exposed to more than 2 hours of mid-day sunlight, had a higher severity score of more than $25^{\text {th }}$ centile, while only $60.0 \%$ of participants who had less than 2 hours exposed to mid-day showed higher MASI scores, with a statistically significant correlation between duration of sun exposure and the severity of melasma. $(p=0.03)$. The use of facial cosmetics also showed a significant correlation with higher melasma severity scores with $81.4 \%$ of participants who use cosmetics having a MASI score of higher than $25^{\text {th }}$ centile, while $59.3 \%$ of those who do not use facial cosmetics show higher scores. $(p=0.002)$ (Table 4). Other factors, namely, pregnancy, hormonal treatment and menstrual irregularity did not show a significant correlation with melasma severity.
Mean Melasma Quality of Life Score (MELASQOL) was 28.86 with most participants reported feeling depressed. There was no significant correlation between melasma severity (MASI) and quality of life (MELASQOL). (Pearson correlation $=0.548, p>0.05$ )

Both age and educational levels correlated with quality of life. $58.8 \%$ individuals who are less than 55 years had more than $50^{\text {th }}$ centile of quality of life score, whereas only $38.4 \%$ participants who are more than 55 years had more than $50^{\text {th }}$ centile of quality of life score, which shows a significant correlation of higher impairment of quality of life with lower age group. $(p=0.012)$. In the sample, $57.6 \%$ of individuals with higher educational level than primary schooling shows higher impairment of quality of life score of more than $50^{\text {th }}$ centile, while only $33.3 \%$ of those who had primary education or below showed higher impairment of quality of life, which is statistically significant. $(p=0.004)$ (Table 5). 
Table 4: The association between aggravating factors and melasma severity

\begin{tabular}{|c|c|c|c|c|c|c|c|}
\hline \multirow{3}{*}{ Characteristics } & \multicolumn{6}{|c|}{ MASI } & \multirow{3}{*}{$p$-value } \\
\hline & \multicolumn{2}{|c|}{ Mild } & \multicolumn{2}{|c|}{$\begin{array}{c}\text { Moderate / Severe / } \\
\text { Very severe }\end{array}$} & \multicolumn{2}{|c|}{ Total } & \\
\hline & $\mathbf{n}$ & $\%$ & $\mathbf{n}$ & $\%$ & $\mathbf{n}$ & $\%$ & \\
\hline \multicolumn{8}{|l|}{ Family history } \\
\hline Yes & 5 & 14.7 & 29 & 85.3 & 34 & 100 & \\
\hline No & 46 & 33.3 & 92 & 66.7 & 138 & 100 & $p=0.033$ \\
\hline \multicolumn{8}{|l|}{ Pregnancy } \\
\hline Yes & 5 & 50.0 & 5 & 50.0 & 10 & 100 & \\
\hline No & 44 & 27.8 & 114 & 72.2 & 158 & 100 & $p=0.135$ \\
\hline \multicolumn{8}{|c|}{ Hormonal treatment } \\
\hline Yes & 11 & 34.4 & 21 & 65.6 & 32 & 100 & \\
\hline No & 38 & 28.6 & 95 & 71.4 & 133 & 100 & $p=0.519$ \\
\hline \multicolumn{8}{|c|}{ Menstrual irregularity } \\
\hline Yes & 15 & 44.1 & 19 & 55.9 & 34 & 100 & \\
\hline No & 34 & 25.8 & 98 & 74.2 & 132 & 100 & $p=0.036$ \\
\hline \multicolumn{8}{|l|}{ Sun exposure } \\
\hline$<2$ hours & 24 & 40.0 & 36 & 60.0 & 60 & 100 & \\
\hline$>2$ hours & 27 & 24.1 & 85 & 75.9 & 112 & 100 & $p=0.030$ \\
\hline \multicolumn{8}{|c|}{ Use of facial cosmetics } \\
\hline Yes & 16 & 8.6 & 70 & 81.4 & 86 & 100 & \\
\hline No & 35 & 0.7 & 51 & 59.3 & 86 & 100 & $p=0.002$ \\
\hline
\end{tabular}

Table 5: The association between quality of life and age and educational level

\begin{tabular}{|c|c|c|c|c|c|c|c|}
\hline & \multicolumn{6}{|c|}{ MELASQOL } & \multirow{3}{*}{$p$-value } \\
\hline & \multicolumn{2}{|c|}{$<5^{\text {th }}$ centile } & \multicolumn{2}{|c|}{$>50^{\text {th }}$ centile } & \multicolumn{2}{|c|}{ Total } & \\
\hline & $\mathbf{n}$ & $\%$ & $\mathbf{n}$ & $\%$ & $\mathbf{n}$ & $\%$ & \\
\hline \multicolumn{8}{|l|}{ Age } \\
\hline$<55$ years & 33 & 41.3 & 47 & 58.8 & 80 & 100 & \\
\hline$>55$ years & 45 & 61.6 & 28 & 38.4 & 73 & 100 & $p=0.012$ \\
\hline \multicolumn{8}{|l|}{ Educational level } \\
\hline Non / Primary & 36 & 66.7 & 18 & 33.3 & 54 & 100 & \\
\hline Secondary / Higher & 42 & 42.4 & 57 & 57.6 & 99 & 100 & $p=0.004$ \\
\hline
\end{tabular}




\section{Discussion}

Melasma shows a great variety of age distribution in different ethnicities, described in several studies. According to Yalamanchili, et al., the common age group reported was between 31-40 years when they present at the clinic (1). Similarly, one British report shows, the mean age as 38 years (6). Guinot, et al., reported that in Tunisian people, $58 \%$ of women had the onset of disease before thirty years of age and in $87 \%$ the onset was between 20 and 40 years $(2,13)$. In a Brazilian study, the mean age of onset in Brazilian people was 25 to 30 years (10). In India, Singapore and in a global study average age of onset was 30,34 and 38 respectively (13). Compared to these, the age of onset in our study population lies between 40 and 49 years, which is higher.

A clear female predominance was identified in all published studies, generally estimated at around $90 \%$. According to the Yalamanchili, et al., a study conducted in India, $67.9 \%$ of females and $32 \%$ males were affected (1). Guinot, et al., noted 188 women and 9 men affected in the Tunisian population (2). Sivayathorn, et al., reported a female to male ratio of $6: 1$ in a Malaysian population and $24: 1$ in an Indonesian population (7). Brazil shows $39: 1$ and Singapore shows $21: 1$ preponderance (13). In our study, cases of melasma reported in men were amounting to $2.3 \%$ with Male female ratio of $1: 42$. The Indian studies only showed a lesser prevalence in females than males, whereas others show more or less similar results as our population.

Malar pattern was the predominantly involved pattern reported in our study. According to Yalamanchili, et al., study in India, the malar pattern is the commonest $(68 \%)$ which is much similar to our study results (1). This is in contrast to the Tunisian study where $76 \%$ of the sample reported centro-facial type (2). Brazil's population showed a predominance of centro-facial type (51.7\%). The pattern exhibited regional variation in a study done in India showing mandibular pattern with 1.6\% only among patients from the northern region in India (7).

Considering the associated factors, our study shows a positive family history of $19.8 \%$. However, positive family history was reported with a very wide range in past studies published in other countries being $10 \%$ in Singapore, $18 \%$ to $33 \%$ in India, $48 \%$ worldwide and $61 \%$ in UK $(1,6,13)$. In our study, positive family history was significantly associated with the severity of melasma.

Pregnancy is a well-known factor associated with melasma. Though in our study only $10.4 \%$ were declared it as an aggravating factor, prevalence of melasma during pregnancy shows wide variation according to population and ethnicities such as $51 \%$ in Tunisians, $16 \%$ in Iranians, $36.4 \%$ in Brazilians, $37 \%$ in Moroccan and $46 \%$ in Pakistanis $(2,13)$. Melasma has been reported to represent around two-thirds of cutaneous side effects of oral contraceptives and the incidence varies according to ethnic groups, showing 38\% in Tunisia and $16.2 \%$ in Brazil $(2,13,14)$. According to this study, 19.4\% of participants declared to have taken OCP at one stage of their life.

Even though multiple causative factors have been implicated in the aetiology, UV radiation is the single most important factor mentioned in the literature. Pathak, et al., reported that exposure to sunlight exacerbated melasma in $100 \%$ of patients (7). In Orientals, $72.4 \%$ of patients reported exacerbation due to sun exposure, whereas in India it shows $55.1 \%$ (7). Tunisian study showed it as an aggravating factor in $84 \%$ but Brazil showed only in $27.2 \%(13,14)$. In our study population, $44.7 \%$ of individuals reported having an exacerbation following sun exposure and the hours of sun exposure amounted to a significant correlation with MASI score.

A review of the recent literature shows that sun exposure was reported as a triggering factor by $51 \%$ an aggravating factor by $84 \%$ (2). Similarly, sun exposure was the most frequently reported factor $(44.7 \%)$ in our study population, as an aggravating factor than others and almost all declared having exposed their skin to the sun in the day time and majority of them (65.1\%) declared that their average sun exposure per day is more than 2 hours.

Only $31.4 \%$ actively use a sun protection method and among them, $85.2 \%$ used sunshades and clothes, however, only $14.8 \%$ declared that they use sunscreens during the sunny period, which is well below than of a study in India which declared 57\% 
use of sun protection methods (2). This shows that awareness towards sun protection methods and sunscreen use is inadequate in our population.

Concerning skin care habits, 50\% declared regular application of cosmetics to face, with herbal and non-herbal products in almost equal amounts $(48.6 \%$ and $45.7 \%$ respectively). It is alarming that, despite the use of regular application of cosmetic products among the study participants, many were not aware of the importance of sunscreens in line with treatment and prevention of melasma which has pigmentary and photo-aging pathogenesis.

The mean MASI score in our study was 12.7 \pm 7.07 . Guinot, et al., also noted similar responses in his study with mean MASI score of 10.1 \pm 6.2 (2), but in contrast, the Indian population showed a much lower level at 5.7 (1). In our population, positive family history, use of cosmetics and the duration of sun exposure were significantly associated with severity scores of melasma.

Comparing the quality of life with other studies, we noted a similar response in the MELASQOL which was 28.86 with most patients reported feeling depressed causing psychosocial and emotional distress. Mean MELASQOL score was 28.28 with the majority reporting embarrassment and frustration in the study done in India and it showed a significant negative impact on the quality of life (1). A study conducted in Brazil using MELASQOL reported that facial lesions can cause low self-esteem, dissatisfaction, withdrawal from social life and lower productivity (13). Also, we noted, the lower age and higher educational level are correlated with higher impairment of quality of life. This implicates more educated people and younger people have more concerns about their appearance.

Although melasma affects the quality of life, according to the data from our population, the severity score of melasma does not correlate to the score of quality of life, suggesting that the subjective perception affects the quality of life than the clinical impression of the disease. This poor correlation was documented in the previous studies as well (13).

\section{Limitations}

The study was carried out among the clinic attendees at Teaching Hospital Karapitiya, therefore the findings may not be generalised to the whole population of the country.

\section{Conclusion and recommendations}

Comparing with other global studies, the age of onset of melasma is higher in our study population and it causes a significant negative effect on psychosocial aspects of quality of life, although, the effect is not related to the clinical severity. This warrants that the treatment decision should not be made by the severity scores of the disease.

Sun exposure was the major aggravating factor identified in this study population. Therefore, the key element in the prevention of melasma involves taking measures to minimize sun exposure, which need to be addressed in our population.

Although half of them use cosmetic products to face; sunscreens usage seems inadequate in the Sri Lankan population, showing the lack of awareness about sunscreens as a prevention method of photo aggravating dermatoses. Therefore, the gravity for protection from the sun should be a key factor to address from the young age.

\section{Acknowledgements}

To the dedicated contribution of the participants of the study to Dr. Rajesh Balkrishnan, copyright holder of English MELASQOL questionnaire and Dr. Champa Wijesinghe and Dr. Thyagi Ponnamperuma, Senior Lecturers in Community Medicine, Faculty of Medicine, University of Ruhuna.

\section{References}

1. Yalamanchili R, Shastry V, Betkerur J. Clinicoepidemiological Study and Quality of Life Assessment in Melasma. Indian Journal of Dermatology, 2015 Sep-Oct; 60(5): 519. 
2. C Guinot, S Cheffai, J Latreille, et al. Aggravating factors for melasma: A prospective study in 197 Tunisian patients. Journal of European Academy of Dermatology and Venereology, 2010; 24: 1060-1069.

3. Kwon SH, Na JI, et al. Melasma: Updates and perspectives Experimental Dermatology, 2019 June; 28(6): 704-708.

4. Ogbechie-Godec, Oluwatobi A, Elbuluk Nada. Melasma: An Up-to-Date Comprehensive Review Dermatology and Therapy, 2017; 7(3); 305-318.

5. Arun Achar, Sanjay K Rathi. Melasma: A clinicoepidemiological study of 312 cases Indian Journal of Dermatology, 2011; 56(4): 380-382.

6. AC Handel, PB Lima, VM Tonolli, LDB Miot, HA Miot. Risk factors for facial melasma in women: A case control study. British Journal of Dermatology, 2014; 171: 588-594.

7. KrupaShankar DS, Somani VK, Kohli M, et al. A crosssectional, multicentric clinico-epidemiological study of melasma in India. Dermatology and Therapy, March 2014; 4(1): 71-81.

8. Vidyadhar R Sardesai, Jennifer N Kolte, Babu N Srinivas. A Clinical Study of Melasma and a Comparison of the Therapeutic Effect of Certain Currently Available Topical Modalities for its Treatment. Indian Journal of Dermatology, 2013; 58(3): 239.
9. Grimes PE. Melasma; etiologic and therapeutic considerations. Arch Dermatol, 1995; 131: 1453-1457.

10. Rashmi Sarkar, Shilpa Garg, Rajesh Balkrishnan, et al. Development and validation of a Hindi language health related quality of life questionnaire for melasma in Indian patients. Indian Journal of Dermatology, Venereology and Leprology, 2016; 82(1):

11. Urmila Bhor, Susil Pande. Scoring systems in dermatology. Indian Journal of Dermatology, Venereology and Leprology, 2006; 72(4): 315-321.

12. Proceedings from $9^{\text {th }}$ Conference of Asian Society for Pigment Cell Research (ASPCR) and $26^{\text {th }}$ Annual Academic Sessions of Sri Lanka College of Dermatologists (SLCD).

13. Handel, Ana Carolina, Miot, et al. Melasma; a clinical and epidemiological review. Anais Brasileiros de Dermatologia, 2014; 89(5); 771-782.

14. Tamega Ade A, Miot LD, et al. Clinical patterns and epidemiological characteristics of facial melasma in Brazilian women Journal of the European Academy of Dermatology and Venereology: JEADV, 2013; 27(2): 151-156. 